On the Effect of a High Frequency Oscillating Field upon the Electrical Resistance of Selenium and Tellurium

This content has been downloaded from IOPscience. Please scroll down to see the full text. 1899 Proc. Phys. Soc. London 17800

(http://iopscience.iop.org/1478-7814/17/1/361)

View the table of contents for this issue, or go to the journal homepage for more

Download details:

IP Address: 159.178.22.27

This content was downloaded on 02/10/2015 at 13:26

Please note that terms and conditions apply. 
LX. On the Effect of a High Freguency Oscillating Field upon the Electrical Resistance of Selenium and Tellurium. $B y$ S. A. F. Whiте, M.A.

\section{[A bstract.]}

A PIECE of selenium, exposed to the action of the field produced between two insulated metal plates attached to the secondary terminals of a Tesla coil, has its electrical resistance increased. A specimen whose original resistance is low (of the order 100 to $1000 \mathrm{ohms}$ ), on exposure to a strong field or to the actual passing of a spark from one of the plates, is immediately and permanently converted into one of high resistance (of the order megohms).

When in this condition or if the original resistance of the specimen is high, the effect of the field is to notably increase the resistance, but it may again be lowered by exposure to light or by alternate heating and cooling.

The effect of a rise of temperature appears to be two-fold: the conductivity of a piece of low resistance is decreased while that of a piece of high resistance is increased.

The effect of the oscillating sparls upon a piece of tellurium is to temporarily decrease its electrical resistance.

A rise of temperature produces a large decrease of electrical resistance, but repeated heated and cooling permanently increases the resistance of the specimen. This latter effect depends upon the material employed for the electrodes. It is much greater with copper than with platinum eleotrodes. In the condition of increased resistance, the effect of the spark in producing a temporary fall of resistance is much nore marked. 


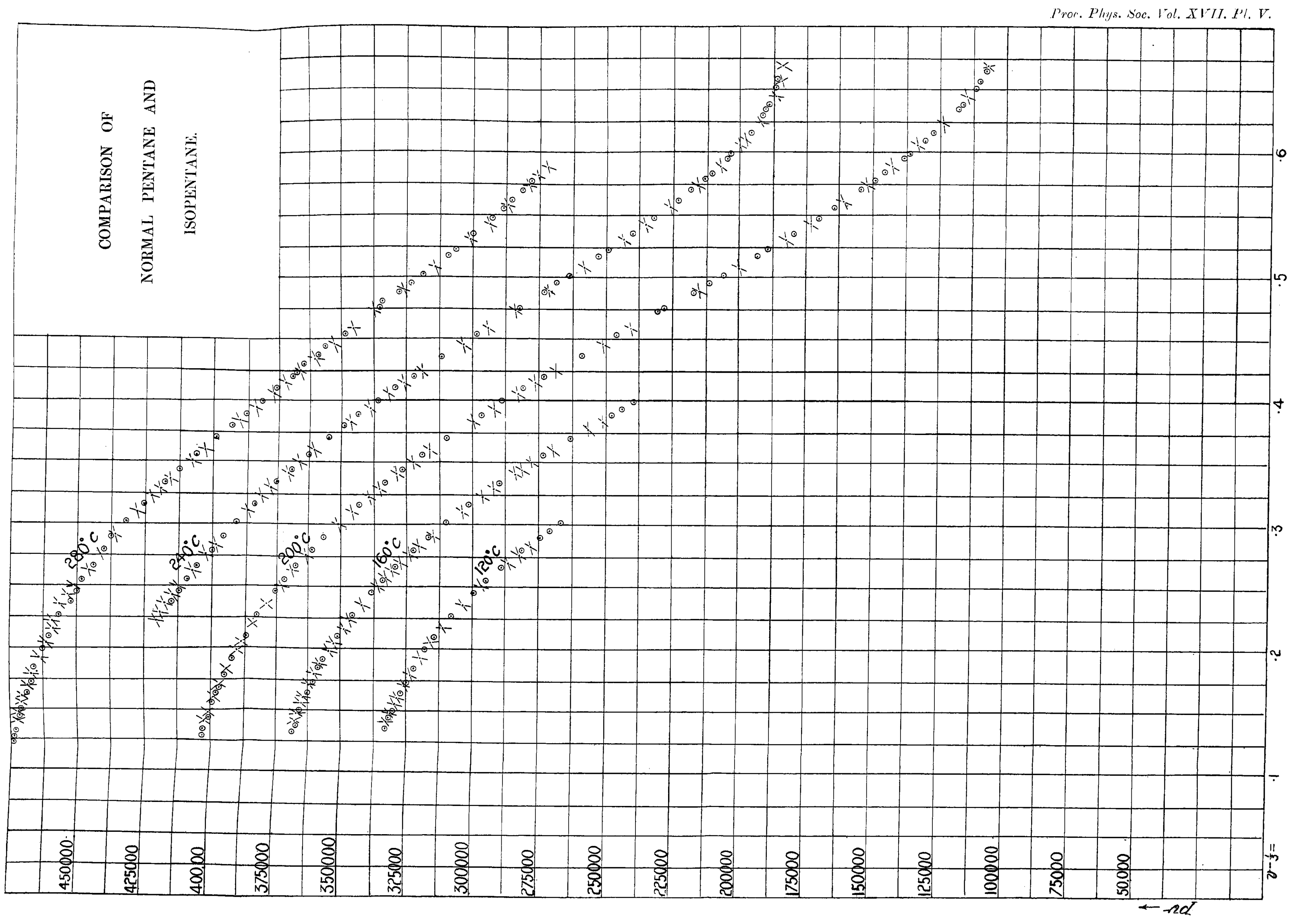




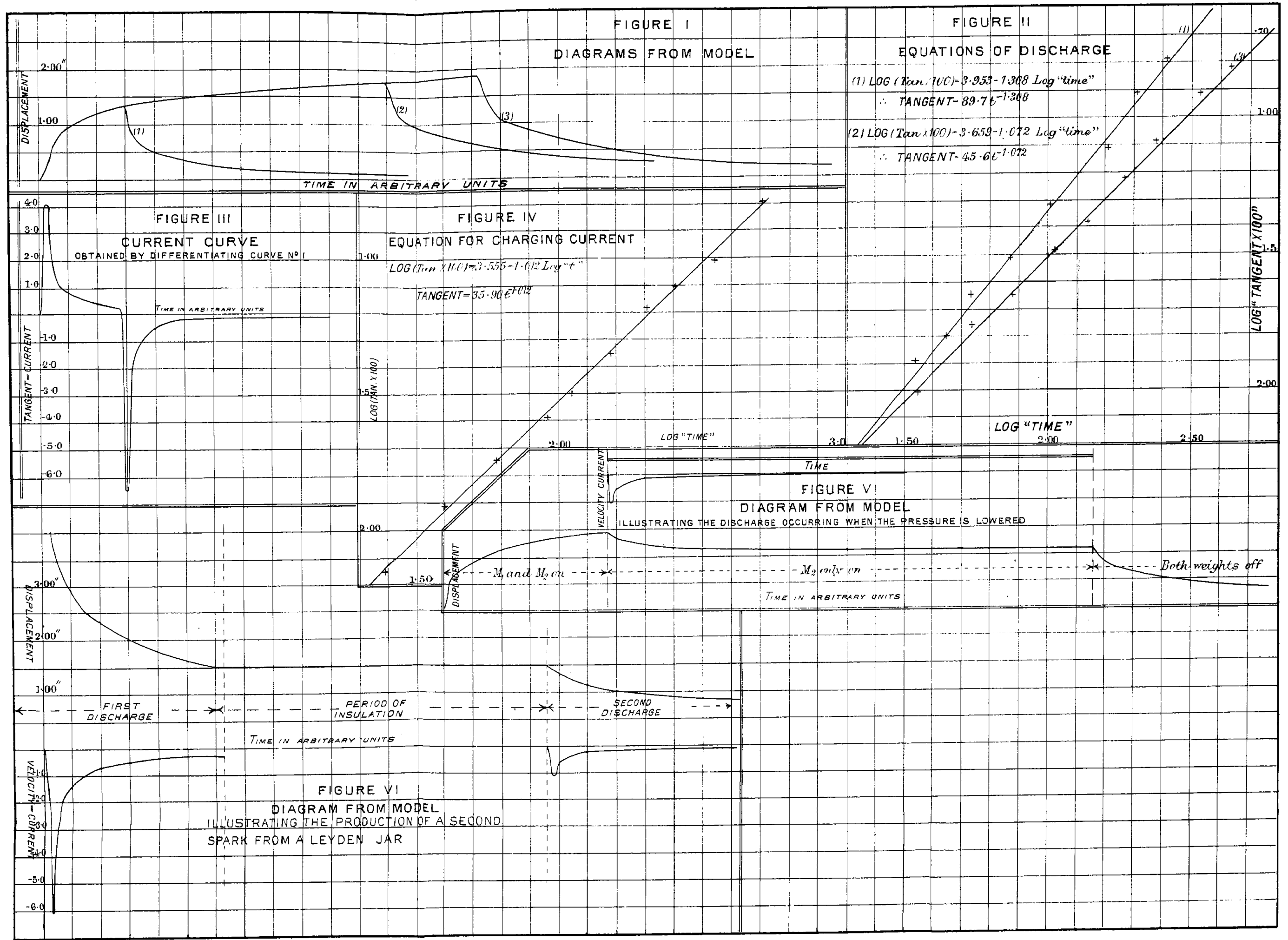

Nintern Bros lith. 